\title{
JABFM Welcomes a New Deputy Editor
}

Marjorie A. Bowman, MD, MPA

(J Am Board Fam Med 2020;33:827-827.)

The Fournal of the American Board of Family Medicine $(7 A B F M)$ would like to introduce our new Deputy Editor, Dr. Dean A. Seehusen, MD, MPH, Professor and Chair of the Department of Family Medicine at Augusta University.

Dr. Seehusen is certainly not new to the fournal. He began peer reviewing for $7 A B F M$ in 2005 and has been frequently named a Top Reviewer. Dean joined the Editorial Board in 2007 and assumed the duties of Associate Editor in 2013.

He earned his medical degree from the University of Iowa and a Master of Public Health from the University of Washington. He is a graduate of the Tripler Army Medical Center Family Medicine Residency and the Madigan Army Medical Center Faculty Development Fellowship in Family Medicine. Dr. Seehusen also served 21 years as an Active-Duty physician in the US Army. He is a decorated combat veteran of wars in both Iraq and Afghanistan.

He has received multiple teaching awards at the graduate medical education and undergraduate medical education levels. He had also received the Society of Teachers of Family Medicine (STFM) Innovation Award and the Lifetime Achieve Award from the Uniformed Services Academy of Family Physicians. Currently, Dean is the Chair of the STFM Research Committee and a member of the STFM Board of Directors. He is a founding member, and Chair, of the Steering Committee for the Council of Academic Family Medicine Educational Research Alliance.

An author of over 125 manuscripts in the peerreviewed medical literature, Dean has also been a peer reviewer for over 30 medical journals and on the editorial teams for Family Medicine, American Family Physician, and the Family Practice Inquiry Network.

With his many wonderful skills and amazing background, Dr. Seehusen is a wonderful addition to the leadership team for $\mathcal{F A B F M}$.

Please join us in welcoming Dr. Seehusen as our new Deputy Editor!

Conflict of Interest: The author is the editor of the $7 A B F M$. 